\title{
MicroRNA-148a Suppresses Invasion and Metastasis of Human Non-Small-Cell Lung Cancer
}

\author{
Jing Lia Tao Yu Jun Cao ${ }^{\mathrm{a}}$ Lei Liu ${ }^{\mathrm{a}}$ Ying Liu ${ }^{\mathrm{a}}$ Han-Wei Kong ${ }^{\mathrm{a}}$ Miao-Xin Zhu \\ He-Chun Lin ${ }^{a}$ Dan-dan Chu ${ }^{a}$ Ming Yao Ming-Xia Yana \\ aState Key Laboratory of Oncogenes and Related Genes, Shanghai Cancer Institute, Renji Hospital, \\ Shanghai Jiao Tong University School of Medicine, Shanghai, 'bepartment of Interventional Oncology, \\ Dahua Hospital, Shanghai, China
}

\section{Key Words}

NSCLC $\cdot$ MiR-148a $\cdot$ Metastasis

\begin{abstract}
Background/Aims: microRNAs (miRNAs) are noncoding RNAs that regulate multiple targets through either the degradation of mRNAs or the inhibition of protein translation, thereby altering several functions simultaneously. Growing evidence indicates that miRNAs are involved in carcinogenesis and tumor progression in non-small-cell lung cancer (NSCLC). Methods: In this study, the mRNA expression levels of miR-148a were examined in NSCLC cell lines and patient specimens using quantitative reverse transcription-PCR. The functions of miR-148a in migration/invasion and lung metastasis formation were determined by using transwell and tail vein injection assays, respectively. Results: We demonstrated that miR-148a was downregulated in NSCLC metastatic samples, and its expression was suppressed in NSCLC compared with the corresponding nonmalignant lung tissues. Clinical analysis indicated that miR-148a expression was lower in NSCLC patients compared with nonmalignant lung tissues. Decreased miR-148a was significantly associated with tumor node metastasis stage and lymph node metastasis. Furthermore, functional assays showed that miR-148a expression suppressed NSCLC cell invasive and migratory abilities in vitro and suppressed cancer metastasis in vivo, while inhibition of miR-148a enhanced NSCLC cell invasion and lung metastasis formation in a mouse model. Conclusions: Evidence from this study demonstrated that miR-148a exerts tumor-suppressive effects in NSCLC and suggests a new therapeutic option for NSCLC.
\end{abstract}




\section{Cellular Physiology Cell Physiol Biochem 2015;37:1847-1856 \begin{tabular}{ll|l} 
and Biochemistry Published online: November 17, 2015 & $\begin{array}{l}\text { (c) } 2015 \text { The Author(s). Published by S. Karger AG, Basel } \\
\text { www.karger.com/cpb }\end{array}$ \\
\hline
\end{tabular} \\ Li et al.: MiR-148a Inhibits Human NSCLC Metastasis}

\section{Introduction}

miRNAs are non-coding, single-stranded RNAs of $\sim 22$ nucleotides that constitute a novel class of gene regulators [1]. The majority of miRNAs lead to translational repression or mRNA degradation through low complementary base-pairing with the 3'UTRs of the target genes [2]. However, some experimental studies have identified miRNA target sites in the coding regions of genes [3]. A single miRNA may target multiple mRNAs, and a single mRNA may have binding sites for multiple miRNAs [1], thus creating a complex regulatory system for biological processes, such as tumor suppressors and oncogenes [4].

A recent study showed that approximately $50 \%$ of annotated human miRNAs are located in areas of the genome, known as fragile sites, which are associated with cancer. This finding indicates that miRNAs might have a crucial function in cancer progression [5]. In addition, accumulating evidence has implicated miRNAs in the invasion and metastasis of a variety of cancers, including gastric cancer, breast cancer, and hepatocellular carcinoma [6-9]. In NSCLC, only a few miRNAs have been identified, including miR-4500, miR-4782-3p, miR-193a,miR-30c , miR-138, and so on [10-14]. Thus, a better understanding of the changes in miRNA expression during NSCLC invasion may lead to a better understanding of NSCLC development, as well as to possible improvements in the diagnosis and treatment of NSCLC.

In a previous study, we established a highly invasive cell subline (SPC-A-1sci) from a weakly invasive cell subline (SPC-A-1) through in vivo selection in NOD/SCID mice [15]. We compared the global miRNA profiles of SPC-A-1sci and SPC-A-1 cells to identify miRNAs that are potentially involved in human NSCLC invasion. A total of 117 miRNAs were differentially expressed in SPC-A-1sci cells relative to SPC-A-1 cells, and miR-148a expression was significantly down-regulated in SPC-A-1sci cells. Recently, miR-148a expression has been reported in several tumors, including gastric cancer, hepatocellular carcinoma, and pancreatic cancer [8, 16-18]. Studies have shown that miR-148a suppresses epithelial-to-mesenchymal transition in non-small cell lung cancer cells $[19,20]$. However, the potential roles and related target genes of miR-148a in human NSCLC metastasis are still poorly understood.

\section{Materials and Methods}

\section{Cell culture}

The human lung cancer cell line SPC-A-1 was obtained from Cellular Institute of Chinese Academy of Science(Shanghai, China). SPC-A-1 was originally isolated from the surgical specimens of a Chinese man with advanced lung adenocarcinoma by Shanghai Chest Hospital and Cellular Institute of Chinese Academy of Science [21]. The highly invasive human lung cancer cell line SPC-A-1sci was established by Ming Yao (Shanghai Jiaotong University, Shanghai Cancer Institute) [15]. A549 and H1299 LC-2, and H358cell were maintained in our laboratory. All cell lines were routinely maintained in DMEM (HyClone) supplemented with $10 \%$ fetal bovine serum (Biowest, South America Origin), $100 \mathrm{U} / \mathrm{ml}$ penicillin sodium, and $100 \mathrm{mg} / \mathrm{ml}$ streptomycin sulfate at $37^{\circ} \mathrm{C}$ in a humidified air atmosphere containing $5 \% \mathrm{CO}_{2}$. Cells were used when they were in the logarithmic growth phase.

\section{Cell transfections}

The miR-148a mimics and miR-148a inhibitors used in this study were synthesized by Ribobio (Guangzhou, China). Oligonucleotide transfection was performed using Lipofectamine 2000 reagents according to the manufacturer's instructions (Invitrogen, CA). For migration, invasion, Western blotting assays, and real-time quantitative RT-PCR (qRT-PCR), the cells were collected $48 \mathrm{~h}$ after transfection.

\section{Wound-healing assays}

For the cell motility assay, cells expressing the miR mimic, the miR inhibitor, the miR control and the negative control were seeded in six-well plates to approximately $90 \%$ confluence. A straight scratch in the cell monolayer was carefully performed using a $200 \mu$ l pipette tip to create a wound. The cells were rinsed with PBS and cultured with 1\% FBS in DMEM. The wounded monolayers were then photographed at 0,24 , and $48 \mathrm{~h}$ using a CKX41 microscope (Olympus, Japan) after wounding. The percentage of wounded area that 


\section{Cellular Physiology Cell Physiol Biochem 2015;37:1847-1856

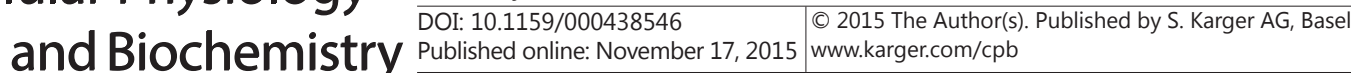 \\ Li et al.: MiR-148a Inhibits Human NSCLC Metastasis}

was filled was calculated as follows: $\{$ (mean wounded breadth - mean remaining breadth)/mean wounded breadth $\} \times 100 \%$.

\section{In vitro migration and invasion assays}

Cell migration and invasion assays were performed in a 24-well plate with 8-mm pore size chamber inserts (Corning, New York, NY, USA). For migration assays, $5 \times 10^{4}$ cells expressing miR-control, negative control, miR mimic and miR inhibitor were placed into the upper chamber per well with the non-coated membrane. For invasion assays, $1 \times 10^{5}$ cells expressing miR-control, negative control, miR mimic and miR inhibitor were placed into the upper chamber per well with a Matrigel-coated membrane, which was diluted with serum-free culture medium. In both assays, the cells were suspended in $200 \mu \mathrm{l}$ of DMEM without fetal bovine serum when they were seeded into the upper chamber. The lower chamber contained $800 \mu$ of DMEM supplemented with $10 \%$ fetal bovine serum. After incubation for some hours at $37^{\circ} \mathrm{C}$ and $5 \% \mathrm{CO}_{2}$, the membrane inserts were removed from the plate, and the non-invading cells were removed from the upper surface of the membrane. The cells that had moved to the bottom surface of the chamber were fixed with $100 \%$ methanol for $20 \mathrm{~min}$ and stained with $0.1 \%$ crystal violet for $30 \mathrm{~min}$. Then, the cells were imaged and counted in at least 10 random fields using a CKX41 inverted microscope (Olympus, Tokyo, Japan). The assays were conducted three independent times.

Establishing stable NSCLC cells

The miR-148a lentiviral vector, miR-148a inhibitor lentiviral vector and miR-control lentiviral vector were synthesized by Genepharma.

In vivo assays for metastasis

For the in vivo metastasis assays, SPC-A-1sci cells stably expressing miR-control or miR-148a lentiviral vector, SPC-A-1 cells transfected with miR-control or miR-148a inhibitor lentiviral vector were inoculated into the tail vein of five-week-old BALB/C-nu/nu nude mice, and the animals were maintained under specific pathogen-free (SPF) conditions. The mice were manipulated and housed according to protocols approved by the Shanghai Medical Experimental Animal Care Commission. Each tumor cell subline was injected into twelve mice $\left(2 \times 10^{6}\right.$ per mouse). After eight weeks, the mice were sacrificed, and the lungs were harvested at necropsy and fixed in 10\% neutral PB-buffered formalin ( $\mathrm{pH} 7.4$ ). The fixed samples were then embedded in paraffin, and five non-sequential serial sections were obtained per animal. The sections were stained with $\mathrm{H} \& \mathrm{E}$ and analyzed for the presence of metastases.

\section{RNA isolation and qRT-PCR assays}

miRNA was extracted from human tissue samples and cultured cells using mirVana miRNA Isolation Kit (Ambion, Carlsbad, CA, USA). The expression level of mature miRNAs was separately quantified with specific primers and probes using TaqMan miRNA assays (Applied Biosystems, Carlsbad, CA, USA) according to the manufacturer's instructions and normalized to U6 small nuclear RNA. The assay IDs are as follows: hsa-miR-148a, ID 000470; RNU44, ID001094.

\section{Human NSCLC tissues}

Patient samples in this study were obtained following informed consent, according to an established protocol approved by the Ethic Committee of Shanghai Jiao-Tong University School. The data did not contain any information that may lead to patient identification. A total of 73 NSCLC tissues and matched adjacent noncancerous tissues for RNA extraction was collected at the time of surgery between 2011 and 2012 at the Department of Lung Cancer, Shanghai Chest Hospital affiliated to Shanghai Jiao Tong University (Shanghai, China). Upon resection, human surgical specimens were immediately frozen in liquid nitrogen and stored at $-80^{\circ} \mathrm{C}$. Of these 73 NSCLC tissues, 16 were squamous cell carcinomas, and 57 were non squamous cell carcinomas.

\section{Statistical analyses}

The results are presented as the mean \pm SD. Comparisons of quantitative data were analyzed by Student's t-test between two groups (two-tailed; $\mathrm{P}<0.05$ was considered significant). Chi-square test was used to compare qualitative variables. Analysis was performed with SAS 9.0 for Windows. 


\section{Cellular Physiology Cell Physiol Biochem 2015;37:1847-1856

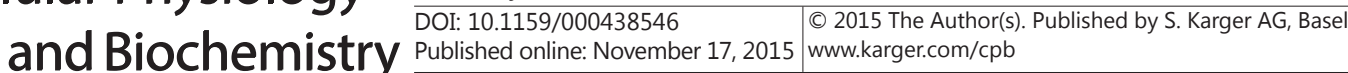 \\ Li et al.: MiR-148a Inhibits Human NSCLC Metastasis}

\section{Results}

MiR-148a expression is downregulated in NSCLC and associated with advanced clinical stage and NSCLC metastasis

To identify metastasis-related miRNAs, we used an miRNA array on SPC-A-1sci and SPC-A-1 cells. After verifying the results through qRT-PCR, we found low expression levels of miR-148a in SPC-A-1sci cells [12]. To further understand the potential biological significance of altered miR-148a expression in NSCLC progression, we evaluated miR-148a expression in 73 pairs of human NSCLC tissues and their corresponding non-tumor tissues by qRTPCR.The relationship between the miR-148a expression levels and the clinicopathological characteristics of the NSCLC patients is summarized in Table 1. The results showed no significant correlations between miR-148a expression and age, gender, or tumor size. We also found that miR-148a expression in NSCLC tissues was lower than in non-tumor tissues and was negatively associated with poorly differentiated tumors, advanced clinical stage, and lymph node metastasis. miR-148a expression was significantly decreased in 42 of 73 tumor samples (55\%, Fig. 1A) compared with the matched normal compartments (Fig. 1B). In addition, we observed a significant decrease in miR-148 expression in NSCLC with clinical advanced stage $(3 / 4 A B, n=37)$ compared with those in early stage $(1 / 2 A B, n=36$; Fig. $1 C)$. Furthermore, miR-148a expression was lower in NSCLC patients with lymphatic metastasis $(\mathrm{n}=30)$ and distant metastasis $(\mathrm{n}=9)$ compared with those without lymphatic metastasis $(\mathrm{n}=34$; Fig. 1D). Taken together, our results indicate that decreased miR-148a expression in NSCLC was associated with advanced clinical stage and lymph node metastasis.

miR-148a inhibits human NSCLC cell invasion and metastasis in vitro.

To clarify the significance of miR-148a in human NSCLC metastasis, we investigated miR-148a expression in 6 human NSCLC cell lines (A549, H1299, SPC-A-1sci, SPC-A-1, LC-2,

Table 1. Correlation Between miR-148a Levels in NSCLC Patients and Their Clinicopathologic Characteristics

\begin{tabular}{|c|c|c|c|}
\hline \multirow{2}{*}{$\begin{array}{l}\text { Clinicopathologic } \\
\text { parameters }\end{array}$} & \multirow[t]{2}{*}{ Number of cases } & \multicolumn{2}{|c|}{$\begin{array}{l}\text { Median expression } \\
\text { of miR-148a }\end{array}$} \\
\hline & & Mean $\pm S D$ & $P$-value \\
\hline \multicolumn{4}{|l|}{ Age(year) } \\
\hline$\leq 60$ & 41 & $12.40 \pm 1.647$ & 0.8247 \\
\hline$>60$ & 32 & $11.85 \pm 1.776$ & \\
\hline \multicolumn{4}{|l|}{ Gender } \\
\hline Male & 45 & $12.15 \pm 1.948$ & 0.8914 \\
\hline Female & 28 & $11.40 \pm 1.737$ & \\
\hline \multicolumn{4}{|l|}{ Tumor size $(\mathrm{cm})$} \\
\hline$\leq 3$ & 35 & $14.64 \pm 1.631$ & 0.0559 \\
\hline$>3$ & 48 & $9.96 \pm 1.771$ & \\
\hline \multicolumn{4}{|l|}{$\begin{array}{l}\text { Degree of } \\
\text { differentiation }\end{array}$} \\
\hline well and moderately & 25 & $14.53 \pm 1.560$ & $0.0168^{*}$ \\
\hline poorly & 48 & $9.009 \pm 1.620$ & \\
\hline \multicolumn{4}{|l|}{ TNM stage } \\
\hline Stage I + II & 36 & $16.12 \pm 2.020$ & $0.0009^{*}$ \\
\hline Stage III+IV & 37 & $8.227 \pm 1.012$ & \\
\hline \multicolumn{4}{|l|}{ Metastasis } \\
\hline No & 34 & $16.38 \pm 2.054$ & $0.0008^{*}$ \\
\hline Yes & 39 & $8.386 \pm 1.086$ & \\
\hline
\end{tabular}




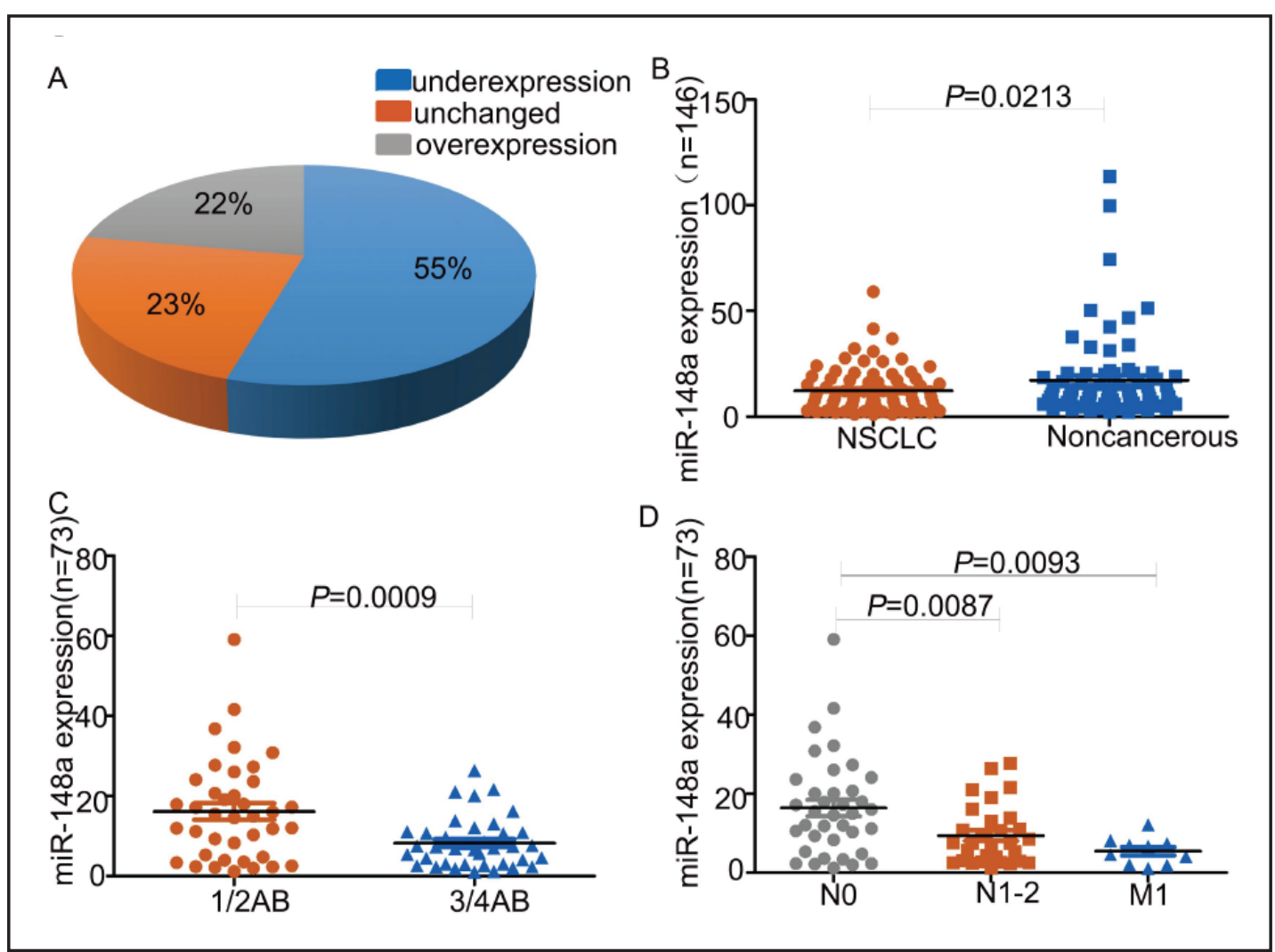

Fig. 1. miR-148a is down-regulated in NSCLC and correlates with advanced clinical stage and tumor invasion and metastasis. (A and B) Relative miR-148a expression was measured using TaqMan real-time PCR in 73 pairs of NSCLC samples and corresponding non-cancerous samples. (C) Real-time PCR analysis to quantify the levels of miR-148a in 73 pairs of NSCLC samples with clinical early-stage $(1 / 2 \mathrm{AB})$ or advanced-stage (3/4AB). (D) Real-time PCR analysis to quantify the levels of miR-148a in 73 pairs of NSCLC samples with lymphatic metastasis $\left(\mathrm{N}_{1-2}\right)$, distant metastasis $\left(\mathrm{M}_{1}\right)$ or without metastasis $\left(\mathrm{N}_{0}\right)$. The results were normalized to an endogenous U6 RNA control. The error bars represent the s.e.m. Statistical analysis was performed using paired t-test (A) and Student's t-test (C and D).

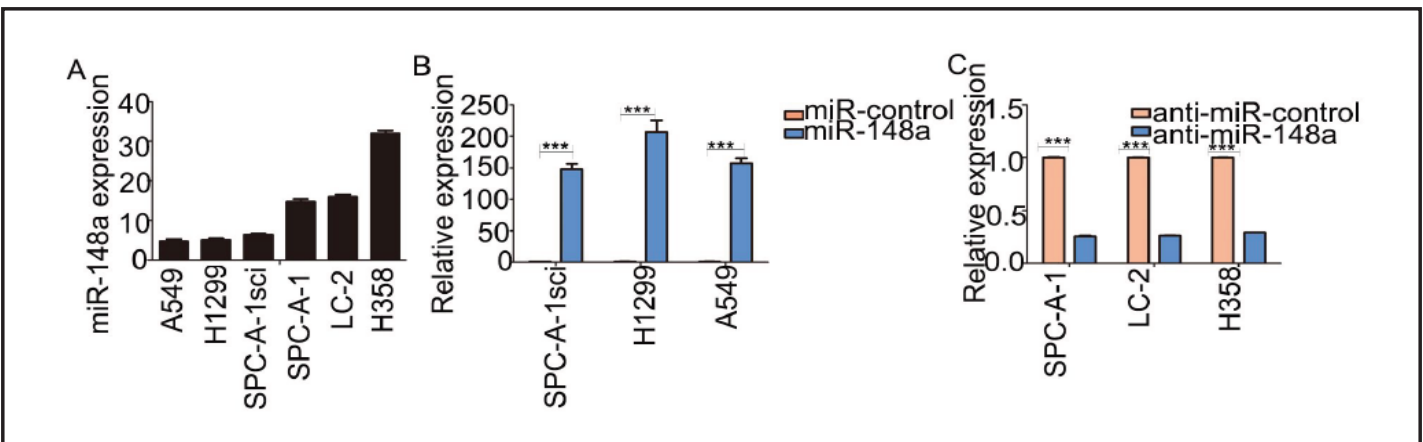

Fig. 2. miR-148a expression levels. (A) miR-148a expression levels in 6 human NSCLC cell lines were measured by quantitative real-time PCR. (B) miR-148a expression was determined by real-time PCR analysis after SPC-A-1sci, H1299, and A549 cells were transfected with the miR-control or miR-148a mimics. (C) miR-148a expression was determined by real-time PCR analysis after SPC-A-1,LC-1,H358 cells were transfected with the miR-control inhibitor or the miR-148a inhibitor. U6 served as an internal control.

and H358) by qRT-PCR. miR-148a expression was higher in the SPC-A-1, LC-2, and H358 cell lines than in the A549, H1299, and SPC-A-1sci cell lines (Fig. 2A). In our previous study, we found that the migration and invasion ability of A549, H1299, and SPC-A-1sci cells was higher 


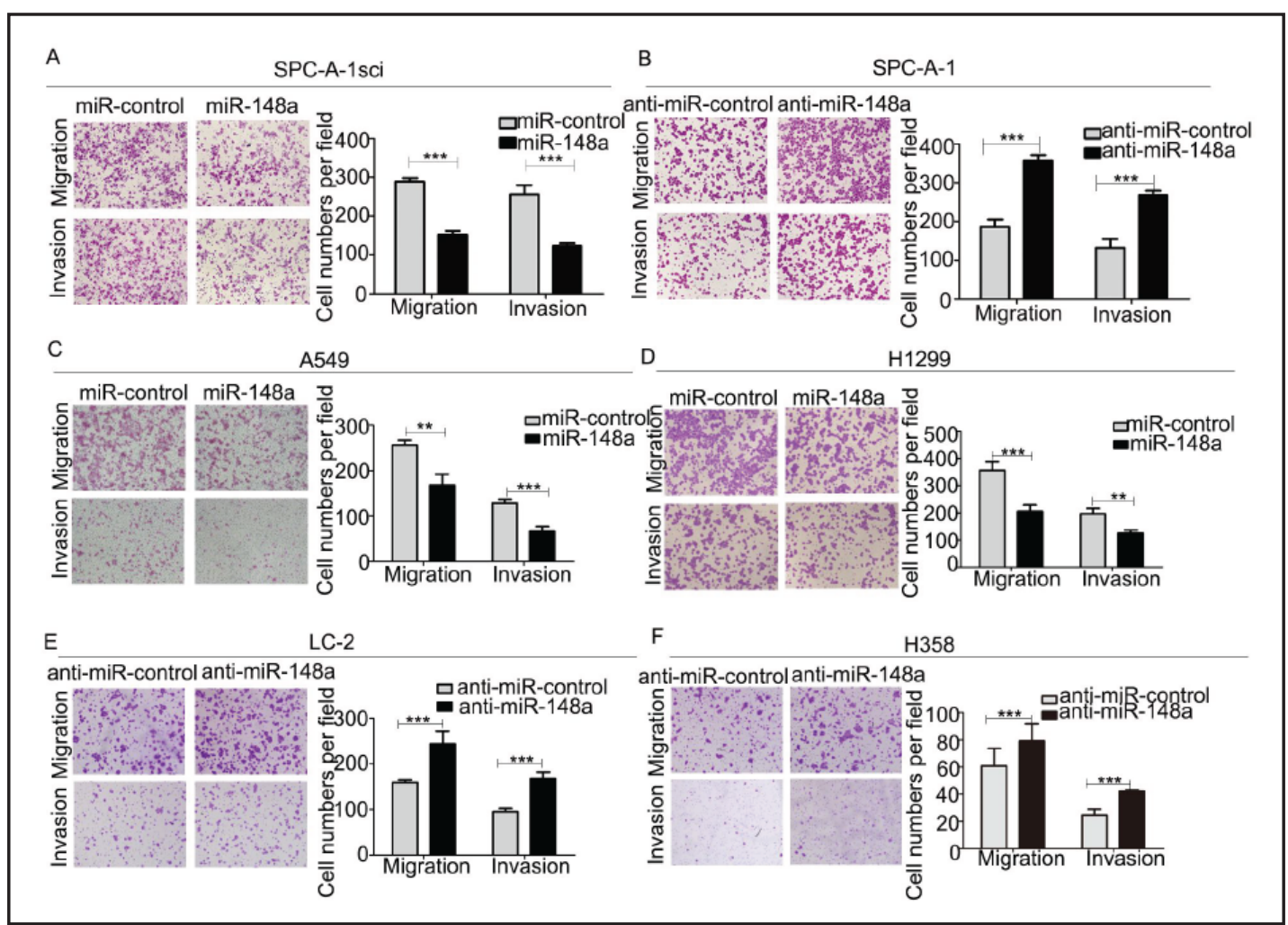

Fig. 3. Transwell migration and invasion assays. (A-F) Transwell migration and invasion assays for SPC-A1sci, H1299, A549, SPC-A-1,LC-2,H358 were determined after transduction with miR controls, miR-148a, anti- miR controls, and anti-miR-148a.The data are representative of three independent experiments. The error bars represent the s.e.m. ${ }^{*} \mathrm{P}<0.05$; ${ }^{* *} \mathrm{P}<0.01{ }^{* * *} \mathrm{P}<0.001$ by Student's t-test.

than that of SPC-A-1, LC-2 and H358 cells using transwell assays with or without Matrigel [12]. These results showed that miR- 148a expression was significantly up-regulated in highly metastatic lung cancer cells (A549, H1299 and SPC-A- 1sci) compared with weakly metastatic lung cancer cells (SPC-A-1, LC-2 and H358).

On the basis of the results showing the suppression of miR-148a expression in high metastatic NSCLC cells, SPC-A-1sci, H1299, and A549 cells were transfected with miR148a mimics (Fig. 2B). The invasion and migration of SPC-A-1sci, H1299, and A549 cells, which were infected with miR-148a mimics, were significantly suppressed compared with the control cells (Fig. 3A, C, D). SPC-A-1,LC-2,H358 cells infected with miR-148a inhibitors (Fig. 2C) showed increased cell invasion and migration (Fig. 3B, E, F). Subsequently, woundhealing assays were applied to determine the migratory abilities of miR-148a, and we also observed that A549, H1299, and SPC-A-1sci cells expressing miR-148a mimics exhibited reduced migration rates compared with the controls (Fig. 4A, C, D). In contrast, miR-148a loss-of-function in SPC-A-1, and LC-2 enhanced the migration rate (Fig. 4B, E),miR-148a loss-of-function in H358 did not enhanced the migration rate (Fig. 4F).Further, we found that up-regulated miR-148a expression significantly enhanced SPC-A-1sci cell growth and clonogenicity (Fig. 5A, C), and down-regulated miR-148a expression inhibited SPC-A-1 cell growth and clonogenicity compared with the miR-control (Fig. 5B, D). These observations suggested that miR-148a promoted human NSCLC cell growth in vitro.

Over-expression of miR-148a impairs the metastasis formation in vivo

To further investigate the function of miR-148a during tumor metastasis in vivo, SPC-A-1 cells transfected with the miR-148a inhibitor or the miR-control inhibitor lentiviral vector 


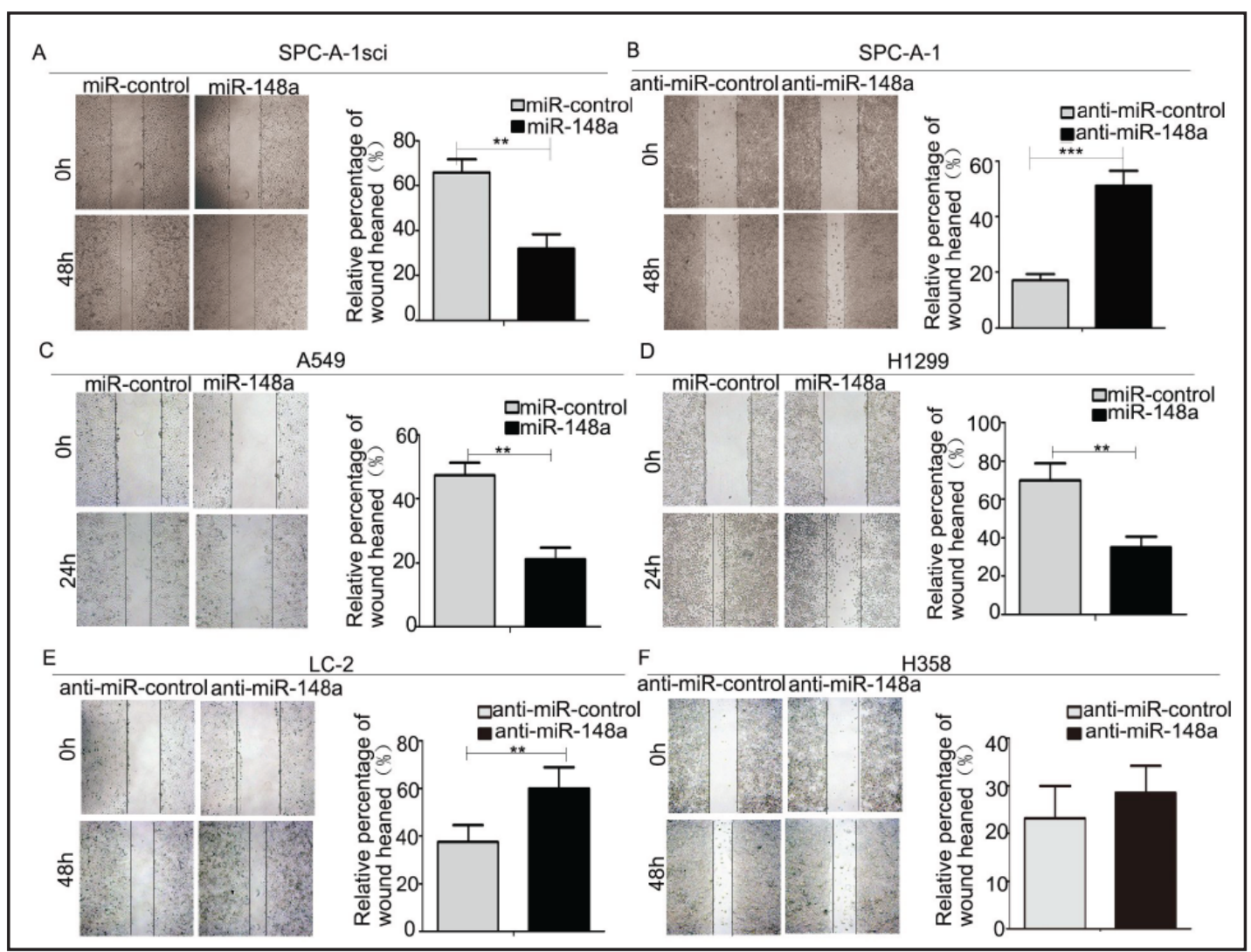

Fig. 4. Wound-healing assay. (A-F) Wound-healing assay for SPC-A-1sci, H1299, A549, SPC-A-1,LC-2,H358 after transduction with the miR controls, miR-148a, anti- miR controls, and anti-miR-148a. The data are representative of three independent experiments. The error bars represent the s.e.m. ${ }^{*} \mathrm{P}<0.05$; ${ }^{* *} \mathrm{P}<0.01$; $* * * \mathrm{P}<0.001$ by Student's t-test.

Fig. 5. miR-148a expression promotes cell proliferation and clonogenicity in lung cancer cells in vitro. (A and C) miR-148a over-expression promoted cell growth according to CCK-8 and cell clonogenicity assays compared with the miR-control transfectants in SPC-A-1sci cell lines. (B and D) miR-148a down-regulation led to cell growth arrest according to CCK-8 assay and inhibited cell clonogenicity compared with the miR-control transfectants in SPC-A-1 cell lines. The data are representative of three independent experiments. The error bars represent the s.e.m. ${ }^{*} \mathrm{P}<0.05$; ** $\mathrm{P}<0.01$; *** $\mathrm{P}<0.001$ by Student's t-test.

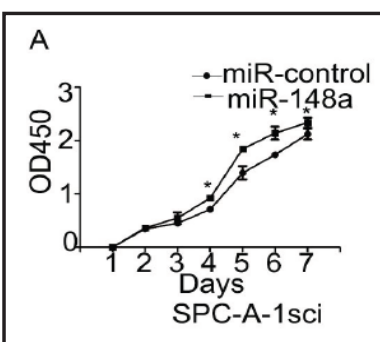

C

miR-control miR-148a
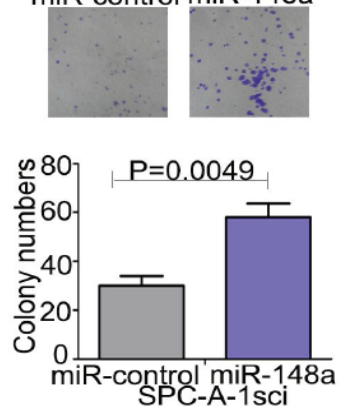

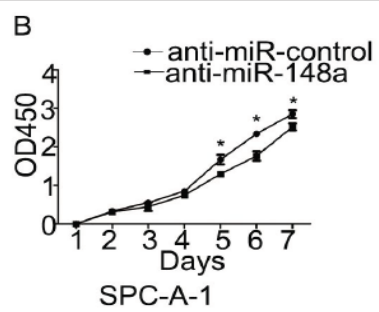

D

anti-miR-control anti-miR-148a
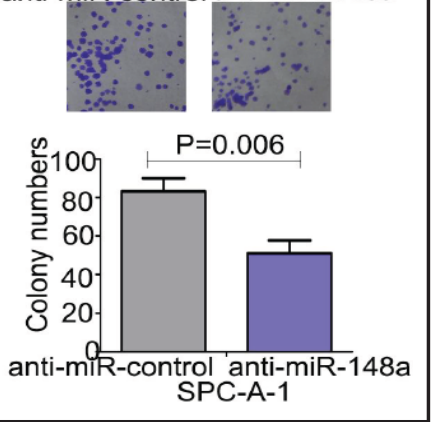

and SPC-A-1sci cells with miR-148a or the miR-control lentiviral vector were injected into nude mice through the lateral tail vein $(n=12$; Fig. 6). Metastatic tumors was significantly decreased in mice that were injected with SPC-A-1 sci cells with the miR-148a lentiviral vector 

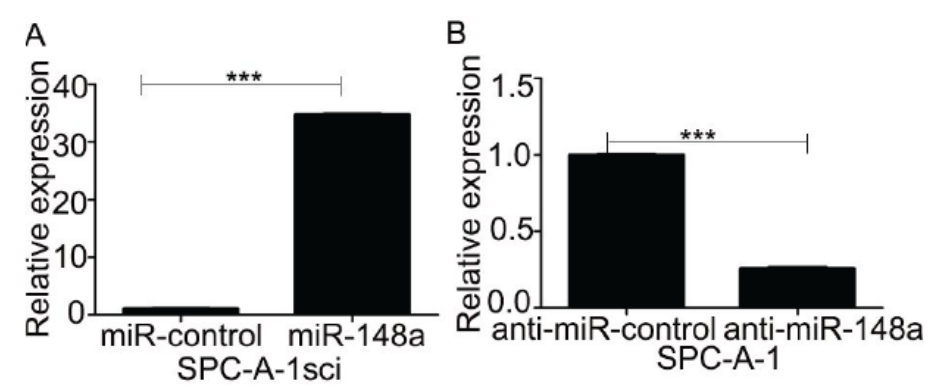

Fig. 6. Levels of miR-148a expression in stable NSCLC cells. (A) miR-148a expression was determined by real-time PCR analysis after SPC-A-1sci cells were transfected with the miR-control or the miR-148a lentiviral vector. (B) miR-148a expression was determined by real-time PCR analysis after SPC-A-1 cells were transfected with the miR-control inhibitor or the miR-148a inhibitor lentiviral vector. U6 served as an internal control.

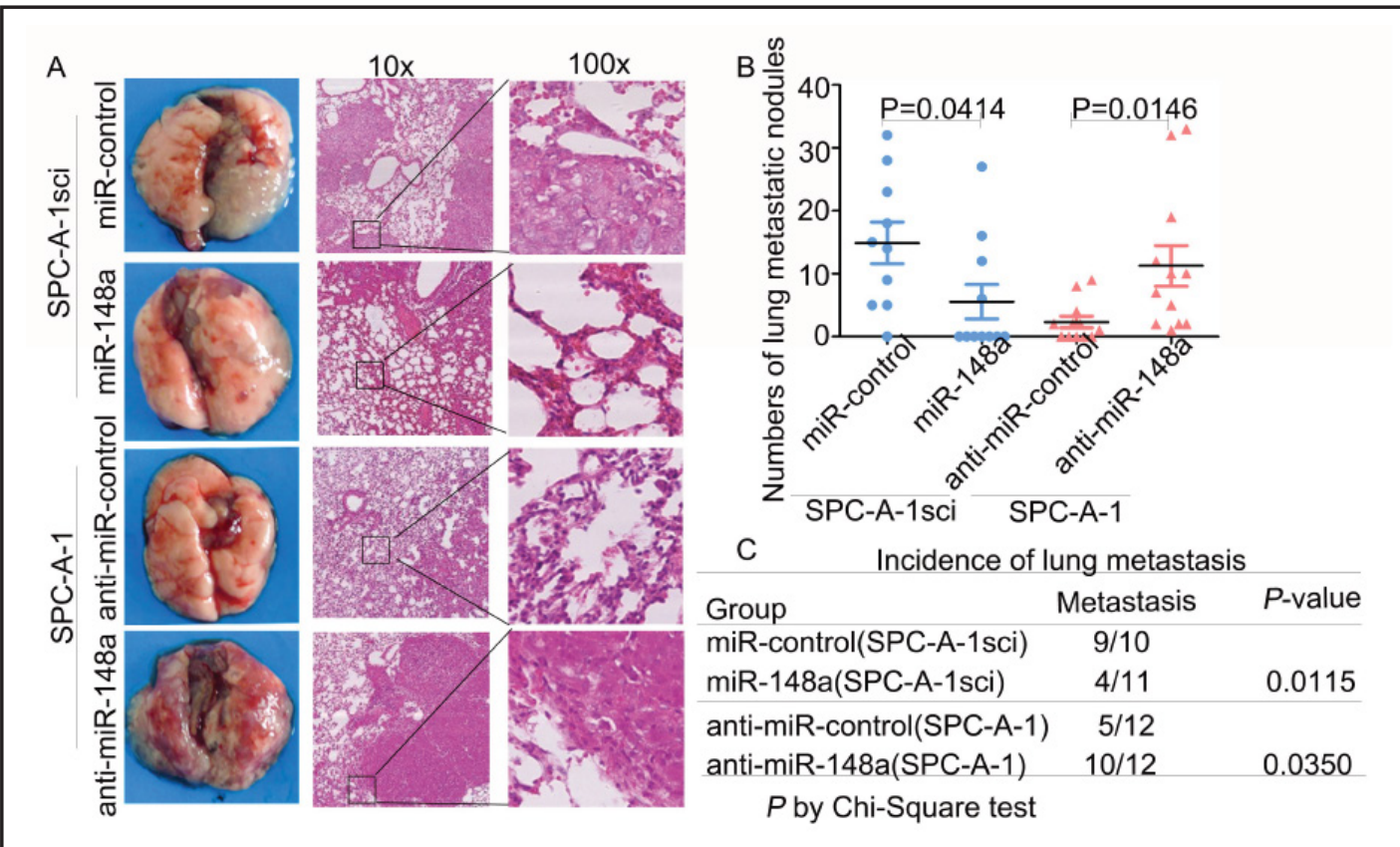

Fig. 7. miR-148a impairs lung metastasis in vivo. (A) Representative images of mouse lungs and images of the histological inspection of mouse lungs for the presence of microscopic lesions after tail vein injection with SPC-A-1sci cells stably expressing miR-148a mimic or the miR-control lentiviral vector and with SPC-A-1 cells stably expressing miR-148a inhibitors or the negative-control lentiviral vector. (B) Quantification of lung microscopic nodules in the lungs of each group. (C) The incidence of metastasis in mice after intravenous tail injections of each cell type is shown in the table. Some mice died naturally under specific pathogen-free (SPF) conditions. The statistical analysis was performed using Student's t-test (B) and the Chi-square test (C). The data are representative of three independent experiments. The error bars represent the s.e.m.

compared with the control group after eight weeks. In stark contrast, lung metastasis was apparent in mice injected SPC-A-1 cells transfected with the miR-148a inhibitor lentiviral vector compared with the negative control group after twelve weeks (Fig. 7A, B). In addition, the ratio of lung metastasis in the miR-148a lentiviral vector group was markedly lower than that of the controls. Conversely, the metastasis rates in the miR-148a inhibitor lentiviral vector group were markedly higher than those in the negative control group (Fig. 7C). Taken together, these results suggest that miR-148a is a negative regulator of NSCLC metastasis.

\section{KARGER}




\section{Cellular Physiology Cell Physiol Biochem 2015;37:1847-1856

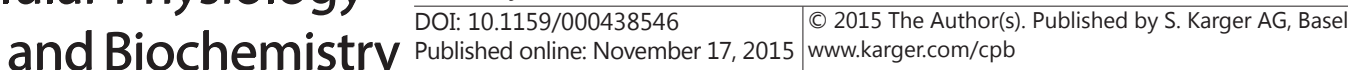 \\ Li et al.: MiR-148a Inhibits Human NSCLC Metastasis}

\section{Discussion}

Metastasis is responsible for the failure of lung cancer therapy and the poor prognosis of lung cancer patients. Therefore, it is essential for us to identify the metastatic factors and understand the molecular mechanisms underlying NSCLC. Growing evidence suggests that miRNAs have important roles in carcinogenesis and metastasis [22]. In the present study, we identified 117 novel metastasis-related miRNAs in NSCLC based on a well-established metastasis cell model [12], and we found that miR-148a was significantly down-regulated in highly metastatic cells.

Previous studies on miR-148a have yielded various results in different cancers. Clinical studies have shown that miR-148a expression is an independent prognostic/predictive biomarker for advanced colorectal cancer patients [23]. Another report showed that miR148a attenuates the paclitaxel resistance of hormone-refractory prostate cancer [24]. In addition, miR-148a promotes apoptosis in colorectal cancer, promotes cell proliferation in gastric cancer, inhibits angiogenesis in breast cancer, and suppresses tumor cell invasion and metastasis in hepatocellular carcinoma and gastric cancer [16, 25-28]. These findings indicate that miR-148a may have important functions in human carcinogenesis. In our study, we observed that miR-148a could suppress the migration and invasion of NSCLC cells in vitro and metastasis in vivo. In addition, miR-148a promoted NSCLC cell proliferation. We also showed that miR-148a was down-regulated in NSCLC tissue samples compared with the corresponding non-cancerous tissues. Furthermore, miR-148a expression was lower in the NSCLC tissue samples with advanced clinical stage and lymph node metastasis. On the basis of these data, we speculated that miR-148a suppressed tumor cell invasion and metastasis in NSCLC.

In summary, miR-148a could suppress NSCLC invasion and metastasis. Importantly, these findings might provide a promising therapeutic target in NSCLC.

\section{Acknowledgements}

We thank Xiang-huo He, and Jin-jun Li for their advices, fruitful discussions. This work was supported by Shanghai Science and Technology Developing Program (13140900502), Natural Science Foundation of China (81472176),and Shanghai Health and Family Planning Commission Research fund (201540158).

\section{Disclosure Statement}

The authors declare no competing interests.

\section{References}

1 Bartel DP: MicroRNAs: genomics, biogenesis, mechanism, and function. Cell 2004;116:281-297.

2 Flynt AS, Lai EC: Biological principles of microRNA-mediated regulation: shared themes amid diversity. Nat Rev Genet 2008;9:831-842.

3 Duursma AM, Kedde M, Schrier M, le Sage C, Agami R: miR-148 targets human DNMT3b protein coding region. RNA 2008;14:872-877.

4 Ambros V: The functions of animal microRNAs. Nature 2004;431:350-355.

5 Calin GA, Sevignani C, Dumitru CD, Hyslop T, Noch E, Yendamuri S, Shimizu M, Rattan S, Bullrich F, Negrini M, Croce CM: Human microRNA genes are frequently located at fragile sites and genomic regions involved in cancers. Proc Natl Acad Sci U S A 2004;101:2999-3004.

6 Goldberger N, Walker RC, Kim CH, Winter S, Hunter KW: Inherited variation in miR-290 expression suppresses breast cancer progression by targeting the metastasis susceptibility gene Arid4b. Cancer Res 2013;73:2671-2681.

7 Yang H, Fang F, Chang R, Yang L: MicroRNA-140-5p suppresses tumor growth and metastasis by targeting transforming growth factor beta receptor 1 and fibroblast growth factor 9 in hepatocellular carcinoma. Hepatology 2013;58: 205-217. 


\section{Cellular Physiology Cell Physiol Biochem 2015;37:1847-1856 \begin{tabular}{ll|l} 
and BiOChemistry & $\begin{array}{l}\text { DOI: 10.1159/000438546 } \\
\text { Published online: November 17, } 2015\end{array}$ & $\begin{array}{l}\text { C } 2015 \text { The Author(s). Published by S. Karger AG, Basel } \\
\text { www.karger.com/cpb }\end{array}$ \\
\hline
\end{tabular} \\ Li et al.: MiR-148a Inhibits Human NSCLC Metastasis}

8 Zhang JP, Zeng C, Xu L, Gong J, Fang JH, Zhuang SM: MicroRNA-148a suppresses the epithelial-mesenchymal transition and metastasis of hepatoma cells by targeting Met/Snail signaling. Oncogene 2014;33:40694079.

9 Hu X, Zhang F, Liu XR, Wu YT, Ni YM: Efficacy and potential microRNA mechanism for computed tomography-guided percutaneous radiofrequency ablation of primary lung cancer and lung metastasis from liver cancer. Cell Physiol Biochem 2014;33:1261-1271

10 Zhang L, Qian J, Qiang Y, Huang H, Wang C, Li D, Xu B: Down-regulation of miR-4500 promoted non-small cell lung cancer growth. Cell Physiol Biochem 2014;34:1166-1174.

11 Wu N, Zhang C, Bai C, Han YP, Li Q: MiR-4782-3p inhibited non-small cell lung cancer growth via USP14. Cell Physiol Biochem 2014;33:457-467.

12 Wang J, Yang B, Han L, Li X, Tao H, Zhang S, Hu Y: Demethylation of miR-9-3 and miR-193a genes suppresses proliferation and promotes apoptosis in non-small cell lung cancer cell lines. Cell Physiol Biochem 2013;32:1707-1719.

13 Xia Y, Chen Q Zhong Z, Xu C, Wu C, Liu B, Chen Y: Down-regulation of miR-30c promotes the invasion of non-small cell lung cancer by targeting MTA1. Cell Physiol Biochem. 2013;32:476-485.

14 Zhang H, Zhang H, Zhao M, Lv Z, Zhang X, Qin X, Wang H, Wang S, Su J, Lv X, Liu H, Du W, Zhou W, Chen X, Fei K: MiR-138 inhibits tumor growth through repression of EZH2 in non-small cell lung cancer. Cell Physiol Biochem 2013;31:56-65.

15 Jia D, Yan M, Wang X, Hao X, Liang L, Liu L, Kong H, He X, Li J, Yao M: Development of a highly metastatic model that reveals a crucial role of fibronectin in lung cancer cell migration and invasion. BMC Cancer 2010;10:364.

16 Liffers ST, Munding JB, Vogt M, Kuhlmann JD, Verdoodt B, Nambiar S, Maghnouj A, Mirmohammadsadegh A, Hahn SA, Tannapfel A: MicroRNA-148a is down-regulated in human pancreatic ductal adenocarcinomas and regulates cell survival by targeting CDC25B. Lab Invest 2011;91:1472-1479.

17 Zheng B, Liang L, Wang C, Huang S, Cao X, Zha R, Liu L, Jia D, Tian Q, Ye Y,Wang Q, Long Z, Zhou Y, Du C, He X, Shi Y: MicroRNA-148a suppresses tumor cell invasion and metastasis by downregulating ROCK1 in gastric cancer. Clin Cancer Res 2011;17:7574-7583.

18 Lujambio A, Calin GA, Villanueva A, Ropero S, Sánchez-Céspedes M, Blanco D, Montuenga LM, Rossi S, Nicoloso MS, Faller WJ, Gallagher WM, Eccles SA, Croce CM, Esteller M: A microRNA DNA methylation signature for human cancer metastasis. Proc Natl Acad Sci U S A. 2008;105:13556-13561.

19 Li J, Song Y, Wang Y, Luo J, Yu W: MicroRNA-148a suppresses epithelial-to-mesenchymal transition by targeting ROCK1 in non-small cell lung cancer cells. Mol Cell Biochem 2013;380:277-282.

20 Joshi P, Jeon YJ, Laganà A, Middleton J, Secchiero P, Garofalo M, Croce CM: MicroRNA-148a reduces tumorigenesis and increases TRAIL-induced apoptosis in NSCLC. Proc Natl Acad Sci U S A 2015;112:86508655.

21 Wu SF, Su JZ, Wang EZ, Xu HX, Ye WQ: Establishment and characterization of human lung cancer cell line SPC-A-1. Science China 1980;10:913-921.

22 Farazi TA, Spitzer JI, Morozov P, Tuschl T: miRNAs in human cancer. J Pathol 2010;223: 102-115.

23 Takahashi M, Cuatrecasas M, Balaguer F, Hur K, Toiyama Y, Castells A, Boland CR, Goel A: The clinical significance of MiR-148a as a predictive biomarker in patients with advanced colorectal cancer. PLoS One 2012; 7:e46684.

24 Fujita Y, Kojima K, Ohhashi R, Hamada N, Nozawa Y, Kitamoto A, Sato A, Kondo S, Kojima T, Deguchi T, Ito M: MiR-148a attenuates paclitaxel resistance of hormone-refractory, drug-resistant prostate cancer PC3 cells by regulating MSK1 expression. J Biol Chem 2010;285:19076-19084.

25 Gailhouste L, Gomez-Santos L, Hagiwara K, Hatada I, Kitagawa N, Kawaharada K, Thirion M, Kosaka N, Takahashi RU, Shibata T, Miyajima A, Ochiya T: miR-148a plays a pivotal role in the liver by promoting the hepatospecific phenotype and suppressing the invasiveness of transformed cells. Hepatology 2013;58:1153-1165.

26 Yu J, Li Q, Xu Q, Liu L, Jiang B: MiR-148a inhibits angiogenesis by targeting ERBB3. J Biomed Res 2011;25:170-177.

27 Guo SL, Peng Z, Yang X, Fan KJ, Ye H, Li ZH, Wang Y, Xu XL, Li J, Li J,Wang YL,Teng Y,Yang X: miR-148a promoted cell proliferation by targeting p27 in gastric cancer cells. Int J Biol Sci 2011;7:567-574.

28 Zhang H, Li Y, Huang Q, Ren X, Hu H, Sheng H, Lai M: MiR-148a promotes apoptosis by targeting Bcl-2 in colorectal cancer. Cell Death Differ 2011;18:1702-1710. 